\title{
Implication of human herpesviruses in oncogenesis through immune evasion and supression
}

\author{
Kenneth Alibek ${ }^{1,2}$, Yeldar Baiken ${ }^{1}$, Ainur Kakpenova ${ }^{1 *}$, Assel Mussabekova', Samal Zhussupbekova ${ }^{1}$, Madina Akan ${ }^{1}$ \\ and Bolat Sultankulov ${ }^{1}$
}

\begin{abstract}
All human herpesviruses (HHVs) have been implicated in immune system evasion and suppression. Moreover, two HHV family members, i.e. EBV and KSHV, are recognised as oncogenic viruses. Our literature review summarises additional examples of possible oncogenic mechanisms that have been attributed to other HHVs. In general, HHVs affect almost every cancer-implicated branch of the immune system, namely tumour-promoting inflammation, immune evasion, and immunosuppression. Some HHVs accomplish these effects by inhibiting apoptotic pathways and by promoting proliferation. Mechanisms related to immunosupression and low grade chronic inflammation could eventually result in the initiation and progression of cancer. In this article we open a discussion on the members of Herpesviridae, their immune evasion and suppression mechanisms, and their possible role in cancer development. We conclude that discerning the mechanisms of interplay between $\mathrm{HHV}$, immune system, and cancer is essential for the development of novel preventative and therapeutic approaches for cancer treatment and prophylaxis.
\end{abstract}

Keywords: Herpesviruses, Cancer, Immune system, Antigen presentation, Natural killer cells, Cytokine

\section{Introduction}

The human herpesviruses include herpes simplex viruses (HSV-1 and HSV-2), varicella zoster virus (VZV), Epstein-Barr virus (EBV), cytomegalovirus (CMV), human herpesvirus 6 and 7 (HHV-6, HHV-7) and Kaposi's Sarcoma-associated herpesvirus (KSHV). Herpesviruses have acquired the unique ability to exploit a number of immune evasion strategies. These strategies enable herpesviruses to persist in a latent state within host cells, and then reactivate under certain conditions. The significance of herpesvirus research is enhanced by accumulating data that associate these viruses with certain types of cancer [1]. Some of the members of Herpesviridae, such as EBV and KSHV, are officially recognized as carcinogens [1]. The role of CMV is well-established in brain tumours, with evidence pointing to several oncogenic mechanisms [2]. Other members of the Herpesviridae

\footnotetext{
* Correspondence: akakpenova@nu.edu.kz

${ }^{1}$ Nazarbayev University, 53 Kabanbay Batyr Avenue, Astana 010000, Kazakhstan

Full list of author information is available at the end of the article
}

family are associated with a malignant phenotype, but their role in carcinogenesis remains unclear and requires further investigation. There are several direct carcinogenic mechanisms exploited by herpesviruses, including inhibiting apoptosis and tumour suppressor pathways, promoting the oncogenic microenvironment, facilitating cellular migration, metastasis, angiogenesis, and inducing mutagenesis (see Table 1).

Another important topic of research is the apparent link between herpesviruses and changes in the immune system. Research has shown that almost every branch of the immune system is affected by herpesvirus proteins, microRNAs, or other products. Clinical evidence shows that herpesviruses lead to immunosuppression and are especially harmful in immunocompromised individuals. There is also evidence linking herpesvirus latency with immunosenescence $[27,28]$. Considering the importance of immune surveillance in the control of cancer cell growth, one hypothesis is that certain human herpesviruses can lead to cancer initiation and progression 
Table 1 Direct oncogenic mechanisms exploited by human herpesviruses

\begin{tabular}{ll}
\hline Human herpesvirus & Associated cancers \\
\hline Herpes simplex virus 1 & HSV1 was detected in benign and malignant thyroid \\
and 2 (HSV-1 and HSV-2) & $\begin{array}{l}\text { tumours [3], associated with prostate cancer, melanoma } \\
\text { incidence in both men and women [4], associated with } \\
\text { cervical cancer [5] }\end{array}$
\end{tabular}

Human herpesvirus 3, or Varicella zoster virus

Human herpesvirus 4, or
Epstein-barr virus (EBV)

Human herpesvirus 5, or human cytomegalovirus

Human herpesviruses 6 and 7 (HHV6 and HHV7), or roseoloviruses

Human herpesvirus $\mathbf{8}$, or Kaposi's sarcoma associated virus (KSHV)
HIV-positive CNS lymphomas and hypopharyngeal and laryngeal tumours [13-15], rarely post-transplant smooth muscle tumours [16]

Glioblastoma (90\% association), lymphoma, nasopharyngeal cancer, cervical cancer, Kaposi's sarcoma (KS), colorectal carcinoma, prostate cancer, skin cancer, astrocytomas $[17,18]$

Paediatric lymphoma [19]), acute lymphoblastic leukaemia [20], basal cell carcinoma [21], glioma [22]

Kaposi's sarcoma, Multicentric castleman disease (MCD), Primary effusion lymphoma (PEL)
Leukaemia, lymphoma, skin cancer, benign and malignant breast tumours [8]

\section{Direct oncogenic mechanisms}

Induces unscheduled DNA synthesis [6]. In lytically infected cells, both HSV-1 and HSV-2 possess an anti-apoptotic activity, specifically HSV-2 protein ICP1OPK, which inhibits apoptosis through activation of Ras/Raf-1/MEK/ERK pathway [7]

VZV ORF12 activates AP1, a transcription factor that upregulates cellular proliferation [9]. VZV ORF63 inhibits apoptosis by IE63 protein [10]

Nasopharyngeal Carcinoma, Burkitt's Lymphoma and Hodgkin's lymphoma, to lesser extent

RASSF1A promoter methylation, p16 homozygous deletions andmethylation [11,12]
Inducing cell cycle progression, activation cell motility and migration, induces VEGF expression, inhibiting DNA damage repair, inducing chromosomal aberrations, inhibiting apoptotic pathways [2]

Restrains p53 [23], DR7 transform NIH3T3 cells [24], cell cycle arrest at G2/M phase [25], integrate into human chromosome [22]

VIRF3 and ORF73 (LANA) inhibit p53-mediated cell cycle arrest and apoptosis; K13 (ORF71) inhibits extrinsic death-receptor-mediated apoptosis pathway; ORF16 encodes the viral $\mathrm{Bcl}-2$ protein that inhibits apoptosis and suppresses the cellular autophagy pathway [26] by disrupting immune system function and response mechanisms. This review covers the major effects of some human herpesviruses on different branches of the immune system, as well as the mechanisms by which these changes may lead to cancer.

\section{Overview of cancer immune system evasion}

The hypothesis of tumour immunosurveillance was first proposed by Thomas and Burnet in 1957. It stated that the human body employs its natural defences and exhibits immunological resistance to the development of cancer. This immunological response occurs during the early stages of cancer development. The clinically detectable signs of tumour disease can only be seen after the cancerous cells have already evaded the immune response [29]. The following list of observations supports the presence of an immune response against cancerous cells $[30,31]$ :

- Tumour-specific immunity, including cytotoxic T-lymphocytes (CTLs) and antibodies.

- Favourable prognosis in immunocompetent patients.

- Cases of spontaneous regression of certain cancers.

- Strong association between immunodeficiency and cancer.

Furthermore, tumours can escape immunosurveillance by several mechanisms [32]:
- Loss or downregulation of MHC class I molecules.

- Downregulation of tumour antigens.

- Suppressing the immune response by ineffective signals to CTLs.

- Immunosuppressive cytokine release.

The detailed discussion below will show how human herpesviruses have been implicated in cancer initiation and progression using immunosurveillance-based mechanisms.

\section{Human herpesviruses 1 and 2: the herpes simplex viruses (HSVs)}

HSV-1 and HSV-2 have evolved numerous mechanisms to evade host detection and immune responses and usually establish lifelong latency. HSV-1 has been detected in benign and malignant thyroid tumours, while HSV-2 has been found associated with papillary thyroid cancer and the presence of lymph node metastases [3]. Additionally, HSV-2 is associated with prostate cancer, melanoma incidence in both men and women [4], and cervical cancer [5].

HSV-1 and HSV-2 impair the immune system by affecting $\mathrm{T}$-cell receptor signalling. These viruses inhibit the T-cell receptor (TCR)-stimulated formation of a linker required for the activation of a $\mathrm{T}$-cell signalling complex. As a result, TCR-stimulated NF- $\mathrm{kB}$ activation and selective TCR-stimulated interleukin-10 synthesis are inhibited, resulting in favoured viral replication and 
suppressed cellular immunity [33]. HSV has been reported to inhibit the type I interferon response [34], and HSV-1 infected cells can resist T-cell induced apoptosis through expression of the Us5 gene product gJ [35]. The HSV-1 infected cell protein (ICP) 47 blocks the peptide transporter (TAP), preventing access of antigenic peptides into the class I pathway [36]. HSV-1 has also been shown to block CTL-induced Ag-dependent apoptosis [37]. Additionally, infection of human B lymphoblastoid cells (B-LCL) by $\mathrm{HSV}-1$ in vitro resulted in decreased ability to induce $\mathrm{CD} 4+\mathrm{T}$ cell clone proliferation and cytokine secretion through US1 gene expression [38].

\section{Human herpesvirus 3: varicella zoster virus (VZV)}

Herpes zoster is a frequent complication of lymphoreticular malignancy. In immunocompromised patients, varicella may present atypically in the form of disseminated ulcerative or necrotic skin lesions [39]. Also, the duration of replication and virus shedding can be extended, resulting in protracted disease [40]. This complication, like many others, is well-described in advanced stages of leukaemia and lymphoproliferative disorders, particularly after chemotherapy [41].

After initial infection, VZV establishes lifelong latency in the sensory ganglia and reactivates upon immunodeficiency. Some experiments have demonstrated that VZV preferentially infects $\mathrm{T}$ cells, particularly CD4 $\mathrm{T}$ cells $[10,42]$. During initial viraemia, infected CD4 T cells cause down regulation of the histocompatibility complex class I expression and allow VZV to evade the immune system [43]. In addition, infected $T$ cells transport VZV via T-cell trafficking from tonsillar tissue to the skin, where VZV replicates and produces cell-free VZV, resulting in highly infectious skin lesions. Uninfected $\mathrm{T}$ cells also arrive at the infection sites, become primed with cellfree VZV, and mount a systemic immune response in an effort to control the initial infection [44]. Cellular immunity clearly plays a critical role in controlling VZV reactivation, because the two main factors contributing to zoster incidence are age (most likely reflecting immune senescence) and cellular immune compromise due to disease or iatrogenic cause. Also there is high risk of reactivation of infection in immunocompromised patients, such as those with leukaemia, lymphoma and other malignancies.

Although acyclovir is the standard treatment for herpes virus infections, resistance can develop, causing fatality [45]. VZV may exacerbate the condition of cancer patients and worsen prognosis.

\section{Human herpesvirus 4 (Epstein-barr virus (EBV))}

EBV has continued to attract considerable attention due to its oncogenic properties and its association with a number of human malignancies of both epithelial and lymphoid origin $[46,47]$. EBV is associated with particular forms of cancers, such as Nasopharyngeal Carcinoma, Burkitt's lymphoma, and Hodgkin's lymphoma. To lesser extent, EBV can be found with HIV-positive CNS lymphomas, hypopharyngeal and laryngeal tumours, sinonasal undifferentiated carcinoma, malignant melanoma, and gastric carcinoma [13-15]. Also, the majority of posttransplant smooth muscle tumours are associated with EBV [16].

The initial invasion of EBV to B cells occurs via binding of viral gp350 protein to cellular receptor CD21. Primary infection of naïve $B$ cells in the oropharynx leads to a general infection of the circulating $B$ cells in blood [48]. EBV-infected B cells proliferate in response to the latent viral proteins and RNAs [49]. To enter epithelial cells, viral proteins BMRF-2 and gH/gL interact with cellular transmembrane receptors, which initiates fusion of the viral envelope with the epithelial cell membrane allowing EBV invasion of the epithelial cell [50]. Glycoprotein gp42 acts as a tropism switch and is required for B cell infection, but inhibits epithelial cell infection [51].

Both lytic and latent infections are regulated by the immune response. EBV has evolved different strategies in order to evade immune system and establish latency in memory B cells. For example, some infected B cells deregulate latent gene expression and become longlived, latently infected memory B cells [27]. Other strategies include disabling immunogenic latent proteins, expressing lytic proteins that interfere with the antigen processing mechanism and the MHC molecule expression in infected cells, and producing viral homologs of human cytokines $[52,53]$.

EBV induces a strong human leukocyte antigen (HLA) class I-restricted, antigen-specific CD8+ CTL response in infected individuals [54]. It is believed that this response plays an important role in regulating the virus during both primary infection and in the long-term carrier state. EBV can impair CD4+ and CD8+ T-cell recognition by a strong, although not complete, HLA I and HLA II down-modulation. This effect is caused by the activity of BNLF2a,4 BILF1 and BGLF5,1,5, which are expressed at different time points during the lytic cycle. Moreover, the virus actively interferes with the effector T-cell action through the viral IL-10 homolog [52].

The transformation of EBV viral particles, such as Epstein-Barr nuclear antigens (EBNAs), latent membrane proteins (LMPs), and Epstein-Barr virus-encoded small RNA (EBERs), from B cells into latently infected lymphoblastoid cell lines ultimately disrupts host genome regulation. The result includes dysregulation of apoptosis, genetic instability, and constant proliferation [11,12]. These effects can be seen in when the virus is in both lytic and latent cycles. In lymphoproliferative disorders expression of only EBNA 1 is revealed in type I latency [55]. Type II latency shows the expression of EBNAs and 
LMPs [56]. Whereas, in type III latency, all EBNAs and LMPs are expressed mostly associated with EBVpositive post-transplant lymphoproliferative disorders and HIV-associated lymphoproliferative disorders [57].

EBV has been shown to specifically bind to monocytes through a CD21-independent receptor [58]. Also, such interactions resulted in the modulation of cytokine gene expression, e.g., IL-1 and IL-6 production [59], and suppression of the synthesis of TNF- $\alpha$, a pleiotropic cytokine that induces apoptosis and exhibits anticancer activity.

\section{Human herpesvirus 5 (human cytomegalovirus (HCMV))}

HCMV has been linked to numerous cancer types, including glioblastoma (90\% association), lymphoma, nasopharyngeal cancer, cervical cancer, Kaposi's sarcoma, colorectal carcinoma, prostate cancer, skin cancer, and astrocytomas [18]. HCMV can infect many types of immune cells, including monocytes, macrophages, dendritic cells (DCs), and granulocytes. Neutrophils are the major carrier during an acute infection, while monocytes and macrophages are responsible for dissemination and latent virus reservoirs. Tumour-associated macrophages are infected with HCMV within the glioblastoma [2]. HCMVinfected monocytes fail to differentiate into DCs, thereby inhibiting the antigen presentation process [60].

HCMV affects the immune response in a wide variety of ways. HCMV proteins block antigen presentation and the recognition of CTL and NK cells. A functional IL-10 homolog also inhibits the NK cell response [2]. Viral gene products lead to CTL evasion by interfering with TAP. Expression of antigenic peptides during latency is linked to immune "memory inflation," leading to immunosuppression and an inefficient response against new antigens [28]. HCMV miRNA (HCMV-miR-UL112-1) helps the host cell to evade NK cell recognition. HCMV also induces B cell-related immune memory inflation via immunodominant epitopes [61]. Additionally, HCMV induces immunosuppressive M2 type macrophage responses. When residing in monocytes, HCMV blocks cytokine-induced macrophage differentiation, leading to impaired phagocytosis [60].

The viral transcript UL111A encodes two transcripts that bear homology to human IL-10 (latent and active), which function to mimic human IL-10. They inhibit pro-inflammatory cytokine production and decrease the expression of MHC I and II, thus exhibiting immunosuppressive properties. In addition, they stimulate proliferation and differentiation of $\mathrm{B}$ lymphocytes and monocytes. This phenotype helps the virus to establish primary productive infection and contributes to persistent viral shedding [62]. In addition, HCMV induces IL- 6 and TNF- $\alpha$ expression, contributing to oncogenic microenvironment [2].

\section{Human herpesviruses 6 and 7 (HHV-6 and -7)}

Roseoloviruses, HHV6 and HHV7, are linked to many lymphoproliferative cancers as well as other types, including paediatric lymphoma [19], Hodgkin's lymphoma, non-Hodgkin's lymphoma, acute leukaemia [63], basal cell carcinoma [21] and glioma [64]. HHV6 is a T-lymphotropic virus. HHV6 is permissive to neural, epithelial and fibroblast cells in vitro, but has a particular tropism to immune cells, such as CD4+ T cells, monocytes, macrophages, NK cells, and DCs. HHV6 enters through human CD46 receptor, which is important for $\mathrm{T}$ cell response and can induce high proliferation of IL-10 [65]. HHV-6 is then transmitted to CD4+ T cells via monocyte-derived DCs [66]. The virus replicates predominantly in CD4+ T lymphocytes and reduces their proliferation [67]. HHV-6 eventually persists latently in monocytes or macrophage-lineage cells [68]. HHV-7 infects both primary CD4+ T lymphocytes and SupT1 lymphoblastoid T-cell line. This type of infection contributes to cancer development due to an accumulation of cells in gap 2/mitosis (G2/M) phase, polyploidy, and an increased cell size. In HHV7 infected cells due to the cell-cycle regulation, cdc2 is activated, thus preventing cytotoxic T-cells activity and altering immune response [69].

HHV-6 and HHV-7 possess both immunosupressive properties and proinflammatory properties, as indicated by their ability to alter the cytokine expression profile of infected cells. HHV-6A induces IL-18 and IFN $\gamma$ receptors, supresses the apoptotic response-associated cytokines IL- 6 and TNF- $\alpha$, and converts T cells to a Th1 phenotype $[64,65]$. HHV-6A infection also promotes IL-6, IL-8, and TGF- $\beta$ production in cultures of astrocytes [64]. Moreover, viral proteins U22, U51 and U83 resemble human chemokines. As an example, U83 can bind to CCR receptors expressed by leukocytes and thus promote leukocyte infiltration [65,68]. Similarly, HHV-7 affects the immunomodulatory cytokines mentioned above. In the supernatants of infected cells, elevated levels of these cytokines were found. On the other hand, the expression of IL-2 was decreased and overall cytokine-induced cellular proliferative responses were down-regulated by this virus [70].

\section{Human herpesvirus 8 (HHV-8)}

The HHV-8 genome contains 86-87 open reading frames (ORFs) or genes, about quarter of which may play a role in modulation of host immune system. Most of these ORFs are predicted to produce proteins that bear homology to host proteins. Thus, HHV-8 has the potential to elaborately evade host immune response [26,71]. HHV-8 is extensively associated with two human malignancies, KS and PEL. Additionally, the virus sequence has been detected in multiple myelomas and angio-immunoblastic lymphomas using PCR [72]. Development of HHV-8- 
associated cancers is usually linked to immunosuppression [10]. For example, KS occurs about 100 times more frequently in untreated AIDS patients [10,73].

Since HHV-8 is transmitted mainly through saliva, it can infect mucosal-associated macrophages, DCs, lymphocytes and endothelial cells. B cells are the major reservoir for HHV-8 latency, where it resides as an episome and evades host immune responses through several molecular pathways. These molecular pathways can also directly provoke oncogenesis when host immunity is disrupted [10,72,74].

XBP-1s protein, one of the host transcription factors for plasma cell maturation, is also used by HHV-8 for the transcription activation of the lytic switch protein. Thus, HHV-8 appears to have evolved to undergo lytic replication during the differentiation of $\mathrm{B}$ cells. Another factor for B cell differentiation is cellular microRNA (miR)-155. HHV-8 encodes its homolog, known as miR-K12-11, which can play role in modulating processes controlled by cellular micro-RNAs [75]. Due to the sequence-specific regulation and non-immunogenic properties of miRNA, arguably that viruses may apply this strategy to improve the cellular environment for viral infection and pathogenesis [76]. The viral interleukin-6 (vIL-6) protein of HHV-8 has mitogenic properties and supports B cell proliferation [77]. It has broader cell specificity than cellular IL-6 because it does not require the gp-80 alpha subunit of the IL- 6 receptor in order to bind gp130 and activate IL-6 signal transduction $[26,71,78]$.

HHV-8 inhibits MHC class I antigen presentation through $\mathrm{K} 3$ and $\mathrm{K} 5$ proteins, which are expressed during lytic cycle and localized at the endoplasmic reticulum. They contribute to increased endocytosis of MHC I molecules, followed by antigen degradation at the proteasome [71]. There is some evidence that HHV-8 escapes the NK cell response by decreasing expression of NKp30, NKp46, and CD161 receptors [73]. The HHV-8 vOX2 protein also alters cellular uptake by inhibiting the phagocytosis of antibody-coated virus particles by neutrophils. vOX2, encoded by K14, mimics cellular CD200 protein, and binds its receptor CD200R with similar affinity [75].

HHV-8 inhibits the complement system through the KSHVcomplement control protein (KCP) encoded in ORF4 $[26,79]$. KCP is a homolog to RCA proteins that can inactivate $\mathrm{C} 3$ convertases, thus preventing complement activation [71]. KCP inactivates $\mathrm{C} 3$ convertases by speeding up their decomposition. Two forms of C3 convertase, classical and alternative, contain $\mathrm{C} 4 \mathrm{~b}$ and $\mathrm{C} 3 \mathrm{~b}$ components, respectively. KCP can act as a cofactor for proteins that cleave both $\mathrm{C} 4 \mathrm{~b}$ and $\mathrm{C} 3 \mathrm{~b}$. Thus, $\mathrm{KCP}$ inhibits complement cascade by two different mechanisms, first by directly contributing to $\mathrm{C} 3$ convertase decomposition, and second by serving as a cofactor for cleavage proteins of $\mathrm{C} 4 \mathrm{~b}$ and $\mathrm{C} 3 \mathrm{~b}$ [79].

Four of the HHV-8 genes encode for viral interferons (vIRF-1 through 4), which are homologous to cellular interferons. vIRFs repress the immune responses normally mediated by cellular interferons through several mechanisms. First, they prevent transcriptional activation mediated by cellular Ifn. Second, they accelerate degradation of some of the Ifn molecules. Additionally, vIRFs inhibit signalling pathways driven by type I interferons ( $\alpha$ and $\beta$ ) and Ifn- $\lambda$. Finally, these viral interferons can inhibit transcription and apoptosis induced by $\mathrm{p} 53$ and PKR proteins $[26,71,72]$.

In additional to interferon homologs, the HHV-8 genome also contains chemokine homologs. Among the HHV-8 lytic-cycle genes are three chemokines homologs, vCCL-1, vCCL-2 and vCCL-3. They share about $41 \%$ amino acid sequence similarity with $C C$ chemokine macrophage inflammatory protein (MIP)- $1 \alpha$ [71]. These viral chemokines reduce host antiviral response by acting as Th2-cell receptor agonists [26].

\section{Overview of immune system-related oncogenic mechanisms exploited by HHVs}

Human herpesviruses have developed numerous mechanisms of immune evasion. Some of the effects of HHVs on immune system may have implications in cancer initiation and progression. The information presented above

Table 2 Immune-system related oncogenic mechanisms exploited by HHVs

\begin{tabular}{|c|c|c|}
\hline & Immune system-related oncogenic mechanism & HHV(s) implicated \\
\hline \multirow{5}{*}{$\begin{array}{l}\text { Tumour-promoting immuno-suppression and } \\
\text { immune evasion mechanisms }\end{array}$} & Inhibition of antigen presentation & HSV-1, HSV-2, VZV, EBV, HCMV, HHV-8 \\
\hline & $\begin{array}{l}\text { vlL-10 expression or human IL-10 related } \\
\text { immunosuppression }\end{array}$ & HSV-1, HSV-2, EBV, HCMV, HHV-6, HHV-7, HHV-8 \\
\hline & Inhibition of CTL and NK cell responses & All HHV \\
\hline & Inhibition of phagocytosis & HCMV, HHV-8 \\
\hline & Inhibition of complement response & KSHV \\
\hline \multirow[t]{2}{*}{ Tumour-promoting inflammation } & $\begin{array}{l}\text { T and B cell immune memory inflation by the } \\
\text { presence of immunodominant epitopes }\end{array}$ & EBV, HCMV \\
\hline & IL-6 induction & EBV, HCMV, HHV-6, HHV-7, HHV-8 \\
\hline
\end{tabular}


shows that, although each member of Herpesviridae family has unique gene products and pathways, there are some similarities in the mechanisms by which they evade the immune system. Table 2 summarises the two major types of tumour-promoting mechanisms: immune suppression and inflammation. It is also clear that both innate and adaptive immune system pathways are impaired by the actions of HHVs. The combination of these mechanisms may potentially initiate or reinforce a cancer phenotype.

\section{Conclusions}

Our knowledge of the role that human herpesviruses play in cancer initiation and progression is constantly evolving with continued investigation. Although several direct oncogenic mechanisms have been observed, it is clear that herpesviruses can promote tumour initiation and/or progression using mechanisms related to the immune system function and response. It is important to note that both tumour-promoting inflammation and immunosuppression have been implicated in this process. Based on the findings reviewed in this article, it is clear that nearly all branches of the anti-tumour immune response may be exploited by herpesviruses and their gene products. Further studies are needed to elaborate the role of these mechanisms in carcinogenesis and to apply this knowledge in the development of novel cancer therapies.

\begin{abstract}
Abbreviations
HSV: Herpes simplex virus; VZV: Varicella zoster virus; EBV: Epstein-barr virus; HCMV: Human cytomegalovirus; KSHV: Kaposi sarcoma-associated herpes virus; CNS: Central nervous system; ORF: Open reading frame; IE: Immediate early; RASSF1A: Ras association (RalGDS/AF-6) domain family member 1; DR7: VIRF, viral interferon regulatory factor; LANA: Latency-associated nuclear antigen; KS: Kaposi sarcoma; MCD: Multiple castleman disease; PEL: Primary effusion lymphoma; CTL: Cytotoxic T cell; MHC: Major histocompatibility complex; TCR: T cell receptor; TAP: Transporter associated with antigen processing; CD: Cluster of differentiation; gp: Glycoprotein; HLA: Human leukocyte antigen; IL: Interleukin; EBNA: Epstein-barr nuclear antigen; LMP: Latent membrane proteins; EBER: Epstein-barr virus-encoded small RNA; TNF: Tumour necrosis factor; UL: Th - T helper, TGF, XBP, vOX2; NK: Natural killer; DC: Dendritic cell; Ifn: Interferon, VCCL, MIP, macrophage inflammatory protein; KCP: KSHV complement control protein.
\end{abstract}

Competing interests

The authors declare that they have no competing interests.

\section{Authors' contributions}

$\mathrm{KA}, \mathrm{AM}, \mathrm{AK}, \mathrm{YB}, \mathrm{SZ}, \mathrm{MA}$, and $\mathrm{BS}$ performed the literature research and wrote the manuscript. All authors read and approved the final manuscript.

\section{Acknowledgements}

We thank National Medical Holding and PI "Nazarbayev University Research and Innovation System" for financial support.

\section{Author details}

'Nazarbayev University, 53 Kabanbay Batyr Avenue, Astana 010000, Kazakhstan. ${ }^{2}$ National Medical Holding, 2 Syganak Street, Astana 010000 Kazakhstan.
Received: 13 September 2013 Accepted: 7 January 2014

Published: 20 January 2014

\section{References}

1. Moore PS, Chang1 Y: Why do viruses cause cancer? Highlights of the first century of human tumour virology. Nat Rev Cancer 2010, 10(12):878-889.

2. Dziurzynski K, Chang SM, Heimberger AB, Kalejta RF, McGregor Dallas SR, Smit M, Soroceanu L, Cobbs CS, Symposium HG: Consensus on the role of human cytomegalovirus in glioblastoma. Neuro Oncol 2012, 14(3):246-255.

3. Jensen K, Patel A, Larin A, Hoperia V, Saji M, Bauer A, Yim K, Hemming V, Vasko V: Human herpes simplex viruses in benign and malignant thyroid tumours. J Pathol 2010, 221(2):193-200.

4. Thomas F, Elguero E, Brodeur J, Le Goff J, Missé D: Herpes simplex virus type 2 and cancer: a medical geography approach. Infect Genet Evol 2011, 11(6):1239-1242.

5. Haverkos H, Rohrer M, Pickworth W: The cause of invasive cervical cancer could be multifactorial. Biomed Pharmacother 2000, 54(1):54-59.

6. Kulomaa P, Paavonen J, Lehtinen M: Herpes simplex virus induces unscheduled DNA synthesis in virus-infected cervical cancer cell lines. Res Virol 1992, 143(5):351-359.

7. Wales SQ, Li B, Laing JM, Aurelian L: The herpes simplex virus type 2 gene ICP10PK protects from apoptosis caused by nerve growth factor deprivation through inhibition of caspase-3 activation and XIAP up-regulation. J Neurochem 2007, 103(1):365-379.

8. Mina E, Ali Z, Mirsaed M, Reza G, Masood G: Detection of varicella zoster virus (Vzv) in the benign and malignant breast tumors by polymerase chain reaction. International Journal Of Molecular And Clinical Microbiology 2012, 2:153-157.

9. Gilden D, Nagel MA, Cohrs RJ: Persistence of varicella zoster virus DNA in saliva after herpes zoster. J Infect Dis 2012, 205(7):1178. author reply $1178-1179$.

10. Lagos D, Boshoff C: Immunobiology and host response to KSHV infection. In Human herpesviruses: biology, therapy, and immunoprophylaxis. Edited by Arvin A, Campadelli-Fiume G, Mocarski E. Cambridge: Cambridge University Press; 2007. al. e.

11. Perez-Ordoñez B: An update on Epstein-barr virus and nasopharyngeal carcinogenesis. Head Neck Pathol 2007, 1(2):141-145.

12. Ozyar E, Ayhan A, Korcum AF, Atahan IL: Prognostic role of Ebstein-barr virus latent membrane protein-1 and interleukin-10 expression in patients with nasopharyngeal carcinoma. Cancer Invest 2004, 22(4):483-491.

13. Alibek K, Kakpenova A, Baiken Y: Role of infectious agents in the carcinogenesis of brain and head and neck cancers. Infect Agent Cancer 2013, 8(1):7.

14. Shinokuma A, Hirakawa N, Tamiya S, Oda Y, Komiyama S, Tsuneyoshi M: Evaluation of Epstein-barr virus infection in sinonasal small round cell tumors. J Cancer Res Clin Oncol 2000, 126(1):12-18.

15. Sousa H, Pinto-Correia AL, Medeiros R, Dinis-Ribeiro M: Epstein-Barr virus is associated with gastric carcinoma: the question is what is the significance? World I Gastroenterol 2008, 14(27):4347-4351

16. Hussein K, Maecker-Kolhoff B, Donnerstag F, Laenger F, Kreipe H, Jonigk D: Epstein-barr virus-associated smooth muscle tumours after transplantation, infection with human immunodeficiency virus and congenital immunodeficiency syndromes. Pathobiology : journal of immunopathology, molecular and cellular biology 2013, 80(6):297-301.

17. Michaelis M, Doerr HW, Cinatl J: The story of human cytomegalovirus and cancer: increasing evidence and open questions. Neoplasia 2009, 11(1):1-9.

18. Mitchell DA, Xie W, Schmittling R, Learn C, Friedman A, McLendon RE, Sampson JH: Sensitive detection of human cytomegalovirus in tumors and peripheral blood of patients diagnosed with glioblastoma. Neuro Oncol 2008, 10(1):10-18.

19. Loutfy SA, Fawzy M, El-Wakil M, Moneer MM: Presence of human herpes virus 6 (HHV6) in pediatric lymphomas: impact on clinical course and association with cytomegalovirus infection. Virol I 2010, 7:287.

20. Seror E, Coquerel B, Gautheret-Dejean A, Ballerini P, Landman-Parker J, Leverger G, Schneider P, Vannier JP: Quantitation of human herpes virus 6 genome in children with acute lymphoblastic leukemia. J Med Virol 2008, 80(4):689-693.

21. Leite JL, Stolf HO, Reis NA, Ward LS: Human herpesvirus type 6 and type 1 infection increases susceptibility to nonmelanoma skin tumors. Cancer Lett 2005, 224(2):213-219. 
22. Amirian ES, Scheurer ME: Chromosomally-integrated human herpesvirus 6 in familial glioma etiology. Med Hypotheses 2012, 79(2):193-196.

23. Oster B, Bundgaard B, Hupp TR, Höllsberg P: Human herpesvirus 6B induces phosphorylation of $\mathrm{p} 53$ in its regulatory domain by a CK2- and p38-independent pathway. J Gen Virol 2008, 89(Pt 1):87-96.

24. Schleimann MH, Møller JM, Kofod-Olsen E, Höllsberg P: Direct repeat 6 from human herpesvirus- $6 \mathrm{~B}$ encodes a nuclear protein that forms a complex with the viral DNA processivity factor p41. PLoS One 2009, 4(10):e7457

25. Li L, Gu B, Zhou F, Chi J, Wang F, Liu G, Ding C, Xie F, Qing J, Guo Y, et al: Human herpesvirus $6 \mathrm{~A}$ infects human embryonic fibroblasts and induces G2/M arrest and cell death. J Med Virol 2012, 84(4):657-663.

26. Lee HR, Brulois K, Wong L, Jung JU: Modulation of immune system by Kaposi's sarcoma-associated herpesvirus: lessons from viral evasion strategies. Front Microbiol 2012, 3:44.

27. Torti $\mathrm{N}$, Oxenius A: T cell memory in the context of persistent herpes viral infections. Viruses 2012, 4(7):1116-1143.

28. Seckert CK, GriessI M, Büttner JK, Scheller S, Simon CO, Kropp KA, Renzaho A, Kühnapfel B, Grzimek NK, Reddehase MJ: Viral latency drives 'memory inflation': a unifying hypothesis linking two hallmarks of cytomegalovirus infection. Med Microbiol Immunol 2012, 201(4):551-566.

29. Kirkwood JM, Tarhini AA, Panelli MC, Moschos SJ, Zarour HM, Butterfield LH, Gogas HJ: Next generation of immunotherapy for melanoma. J Clin Oncol 2008, 26(20):3445-3455.

30. Peto J: Cancer epidemiology in the last century and the next decade. Nature 2001, 411(6835):390-395.

31. Engels EA, Pfeiffer RM, Fraumeni JF, Kasiske BL, Israni AK, Snyder JJ, Wolfe RA, Goodrich NP, Bayakly AR, Clarke CA, et al: Spectrum of cancer risk among US solid organ transplant recipients. JAMA 2011, 306(17):1891-1901.

32. Rabinovich GA, Gabrilovich D, Sotomayor EM: Immunosuppressive strategies that are mediated by tumor cells. Annual review of immunology 2007, 25:267-296

33. Sloan DD, Jerome KR: Herpes simplex virus remodels T-cell receptor signaling, resulting in p38-dependent selective synthesis of interleukin-10. J Virol 2007, 81(22):12504-12514.

34. Murphy JA, Duerst RJ, Smith TJ, Morrison LA: Herpes simplex virus type 2 virion host shutoff protein regulates alpha/beta interferon but not adaptive immune responses during primary infection in vivo. J Virol 2003, 77(17):9337-9345

35. Jerome KR, Fox R, Chen Z, Sarkar P, Corey L: Inhibition of apoptosis by primary isolates of herpes simplex virus. Arch Virol 2001, 146(11):2219-2225.

36. Früh $K$, Ahn $K$, Djaballah $H$, Sempé $P$, van Endert PM, Tampé $R$, Peterson PA, Yang $Y$ : A viral inhibitor of peptide transporters for antigen presentation. Nature 1995, 375(6530):415-418.

37. Jerome KR, Tait JF, Koelle DM, Corey L: Herpes simplex virus type 1 renders infected cells resistant to cytotoxic T-lymphocyte-induced apoptosis. J Virol 1998, 72(1):436-441.

38. Barcy S, Corey L: Herpes simplex inhibits the capacity of lymphoblastoid B cell lines to stimulate CD4+ T cells. J Immunol 2001, 166(10):6242-6249.

39. Straus SE SK, Oxman MN: Varicella and herpes zoster. In Fitzpatrick's dermatology in general medicine. 6th edition. Edited by Freedberg IM EA, Wolff K, Austen KF, Goldsmith LA, Katz SI. New York: McGraw-Hill Book Co; 2003:2070-2085.

40. Balfour $\mathrm{HH}$ : Varicella zoster virus infections in immunocompromised hosts. A review of the natural history and management. Am J Med 1988 85(2A):68-73.

41. Ferreira M, Sanches M, Teixeira M, Guerra M, Selores M: Persistent varicella as the initial manifestation of systemic lymphoma. Dermatol Online J 2008, 14(2):24

42. Arvin A: Aging, immunity, and the varicella-zoster virus. N Engl J Med 2005, 352(22):2266-2267

43. Arvin AM, Sharp M, Moir M, Kinchington PR, Sadeghi-Zadeh M, Ruyechan WT, Hay J: Memory cytotoxic T cell responses to viral tegument and regulatory proteins encoded by open reading frames $4,10,29$, and 62 of varicella-zoster virus. Viral Immunol 2002, 15(3):507-516.

44. Ku CH, Liu YT, Christiani DC: Case report: occupationally related recurrent varicella (chickenpox) in a hospital nurse. Environ Health Perspect 2005, 113(10):1373-1375.
45. Kurtaran B, Paydaş S, Candevir A, Kömür S, Aksu HSZ: Disseminated herpes zoster infection ina patient with lymphoma. Turk J Med Sci 2009, 39(3):479-482.

46. Rickinson A: Concluding overview: looking back, looking forward. Philos Trans R Soc Lond B Biol Sci 2001, 356(1408):595-604.

47. Gulfaraz K: Epstein-barr virus, cytokines, and inflammation: a cocktail for the pathogenesis of Hodgkin's lymphoma? Experimental Haematology 2005, 34:399-406.

48. Hochberg D, Souza T, Catalina M, Sullivan JL, Luzuriaga K, Thorley-Lawson DA: Acute infection with Epstein-barr virus targets and overwhelms the peripheral memory B-cell compartment with resting, latently infected cells. J Virol 2004, 78(10):5194-5204.

49. Roughan JE, Torgbor C, Thorley-Lawson DA: Germinal center B cells latently infected with Epstein-barr virus proliferate extensively but do not increase in number. J Virol 2010, 84(2):1158-1168.

50. Odumade OA, Hogquist KA, Balfour $\mathrm{HH}$ : Progress and problems in understanding and managing primary Epstein-barr virus infections. Clin Microbiol Rev 2011, 24(1):193-209.

51. Chen J, Rowe CL, Jardetzky TS, Longnecker R: The KGD motif of Epstein-barr virus $\mathrm{gH} / \mathrm{gL}$ is bifunctional, orchestrating infection of $B$ cells and epithelial cells. MBio 2012, 3(1):e00290-11.

52. Merlo A, Turrini R, Dolcetti R, Martorelli D, Muraro E, Comoli P, Rosato A: The interplay between Epstein-barr virus and the immune system: $a$ rationale for adoptive cell therapy of EBV-related disorders. Haematologica 2010, 95(10):1769-1777.

53. Ressing ME, Horst D, Griffin BD, Tellam J, Zuo J, Khanna R, Rowe M, Wiertz EJ: Epstein-barr virus evasion of CD8(+) and CD4(+) T cell immunity via concerted actions of multiple gene products. Semin Cancer Biol 2008, 18(6):397-408.

54. Kuzushima K, Nakamura S, Nakamura T, Yamamura Y, Yokoyama N, Fujita M, Kiyono T, Tsurumi T: Increased frequency of antigen-specific CD8(+) cytotoxic T lymphocytes infiltrating an Epstein-barr virus-associated gastric carcinoma. J Clin Invest 1999, 104(2):163-171.

55. Carbone A, Gloghini A, Dotti G: EBV-associated lymphoproliferative disorders: classification and treatment. The oncologist 2008 13(5):577-585.

56. Thompson MP, Kurzrock R: Epstein-barr virus and cancer. Clinical cancer research : an official journal of the American Association for Cancer Research 2004, 10(3):803-821.

57. Zhang T, Fu Q, Gao D, Ge L, Sun L, Zhai Q: EBV associated lymphomas in 2008 WHO classification. Pathology, research and practice 2013. http:// dx.doi.org/10.1016/j.prp.2013.11.009.

58. Gosselin J, Menezes J, D’Addario M, Hiscott J, Flamand L, Lamoureux G, Oth D: Inhibition of tumor necrosis factor-alpha transcription by Epstein-barr virus. Eur J Immunol 1991, 21(1):203-208.

59. Gosselin J, Flamand L, D'Addario M, Hiscott J, Stefanescu I, Ablashi DV, Gallo RC, Menezes J: Modulatory effects of Epstein-barr, herpes simplex, and human herpes- 6 viral infections and coinfections on cytokine synthesis. A comparative study. J Immunol 1992 149(1):181-187.

60. Gredmark-Russ S, Söderberg-Nauclér C: Dendritic cell biology in human cytomegalovirus infection and the clinical consequences for host immunity and pathology. Virulence 2012, 3(7):621-634.

61. Smith C, Khanna R: Immune regulation of human herpesviruses and its implications for human transplantation. Am J Transplant 2013, 13(3):9-23. quiz 23

62. McSharry BP, Avdic S, Slobedman B: Human cytomegalovirus encoded homologs of cytokines, chemokines and their receptors: roles in immunomodulation. Viruses 2012, 4(11):2448-2470.

63. Ogata M: Human herpesvirus 6 in hematological malignancies. J Clin Exp Hematop 2009, 49(2):57-67.

64. Chi J, Gu B, Zhang C, Peng G, Zhou F, Chen Y, Zhang G, Guo Y, Guo D, Qin J, et al: Human herpesvirus 6 latent infection in patients with glioma. J Infect Dis 2012, 206(9):1394-1398.

65. Reynaud JM, Horvat B: Human herpesvirus 6 and neuroinflammation. ISRN Virology 2013, 2013:11.

66. Takemoto M, Imasawa T, Yamanishi K, Mori Y: Role of dendritic cells infected with human herpesvirus 6 in virus transmission to CD4(+) T cells. Virology 2009, 385(2):294-302.

67. Mori Y: Recent topics related to human herpesvirus 6 cell tropism. Cell Microbiol 2009, 11(7):1001-1006 
68. Zou P, Isegawa $Y$, Nakano K, Haque M, Horiguchi Y, Yamanishi K: Human herpesvirus 6 open reading frame U83 encodes a functional chemokine. J Virol 1999, 73(7):5926-5933.

69. Secchiero P, Bertolaso L, Casareto L, Gibellini D, Vitale M, Bemis K, Aleotti A, Capitani S, Franchini G, Gallo RC, et al: Human herpesvirus 7 infection induces profound cell cycle perturbations coupled to disregulation of cdc2 and cyclin B and polyploidization of CD4(+) T cells. Blood 1998, 92(5):1685-1696.

70. Atedzoé BN, Menezes J, D'Addario M, Xu J, Ongradi J, Ahmad A: Modulatory effects of human herpes virus-7 on cytokine synthesis and cell proliferation in human peripheral blood mononuclear cell cultures. J Leukoc Biol 1999, 66(5):822-828.

71. Rezaee SA, Cunningham C, Davison AJ, Blackbourn DJ: Kaposi's sarcomaassociated herpesvirus immune modulation: an overview. J Gen Virol 2006, 87(Pt 7):1781-1804

72. Cai Q, Verma SC, Lu J, Robertson ES: Molecular biology of Kaposi's sarcoma-associated herpesvirus and related oncogenesis. Adv Virus Res 2010, 78:87-142

73. Dupuy S, Lambert M, Zucman D, Choukem SP, Tognarelli S, Pages C, Lebbé C, Caillat-Zucman S: Human herpesvirus 8 (HHV8) sequentially shapes the NK cell repertoire during the course of asymptomatic infection and Kaposi sarcoma. PLoS Pathog 2012, 8(1):e1002486.

74. Cirone M, Lucania G, Bergamo P, Trivedi P, Frati L, Faggioni A: Human herpesvirus $8(\mathrm{HHV}-8)$ inhibits monocyte differentiation into dendritic cells and impairs their immunostimulatory activity. Immunol Lett 2007, 113(1):40-46.

75. Aresté C, Blackbourn DJ: Modulation of the immune system by Kaposi's sarcoma-associated herpesvirus. Trends Microbiol 2009, 17(3):119-129.

76. Liang C, Lee JS, Jung JU: Immune evasion in Kaposi's sarcoma-associated herpes virus associated oncogenesis. Seminars in cancer biology 2008, 18(6):423-436.

77. Pagano JS, Blaser M, Buendia MA, Damania B, Khalili K, Raab-Traub N, Roizman B: Infectious agents and cancer: criteria for a causal relation. Semin Cancer Biol 2004, 14(6):453-471.

78. Osborne J, Moore PS, Chang Y: KSHV-encoded viral IL-6 activates multiple human IL-6 signaling pathways. Hum Immunol 1999, 60(10):921-927.

79. Mark L, Lee WH, Spiller OB, Proctor D, Blackbourn DJ, Villoutreix BO, Blom AM: The Kaposi's sarcoma-associated herpesvirus complement control protein mimics human molecular mechanisms for inhibition of the complement system. J Biol Chem 2004, 279(43):45093-45101.

doi:10.1186/1750-9378-9-3

Cite this article as: Alibek et al: Implication of human herpesviruses in oncogenesis through immune evasion and supression. Infectious Agents and Cancer 2014 9:3.

\section{Submit your next manuscript to BioMed Central and take full advantage of:}

- Convenient online submission

- Thorough peer review

- No space constraints or color figure charges

- Immediate publication on acceptance

- Inclusion in PubMed, CAS, Scopus and Google Scholar

- Research which is freely available for redistribution 